\title{
The Androchair: Performing Gynaecology through the Practice of Gender Critical Design
}

\section{Karin Ehrnberger, Minna Räsänen, Emma Börjesson, Anne-Cristine Hertz \& Cristine Sundbom}

To cite this article: Karin Ehrnberger, Minna Räsänen, Emma Börjesson, Anne-Cristine Hertz \& Cristine Sundbom (2017): The Androchair: Performing Gynaecology through the Practice of Gender Critical Design, The Design Journal, DOI: 10.1080/14606925.2016.1261510

To link to this article: http://dx.doi.org/10.1080/14606925.2016.1261510

Published online: 05 Jan 2017.

Submit your article to this journal $₫$

Q View related articles ¿

View Crossmark data $₫$ 


\section{The Androchair: Performing Gynaecology through the Practice of Gender Critical Design}

Karin Ehrnberger

Royal Institute of Technology, School of Machine Design, Stockholm, Sweden

Minna Räsänen

School of Natural Sciences, Technology and Environmental Studies, Södertörn University, Huddinge, Sweden

Emma Börjesson Halmstad University, Halmstad, Sweden

Anne-Cristine Hertz Halmstad University, Halmstad, Sweden

Cristine Sundbom Royal College of Arts, Crafts and Design, Stockholm, Sweden 
ABSTRACT This paper highlights the important role that design plays when it comes to women's overall experiences of ther gynaecological examination. It exemplifies how the examination can become renegotiable through the practice of a critical design. We will reflect this in the design of the contemporary gynaecological examination chair (GEC). We used women's experiences as a starting point for the design of an Androchair (a conceptual male equivalent of the GEC), in order to make the experiences critically visible. Inspired by the view of the gynaecological examination as a performance where the Androchair is represented as a prop and was placed on a stage as a discussion object during a public seminar. The Androchair allowed for both critical and multiple readings of the GEC and through that, the gynaecology examination at large. Moreover, it stimulated a discussion about alternative ideas towards achieving a more positive experience.

KEYWORDS: gynaecology, gender critical design, theories of performance

\section{Introduction}

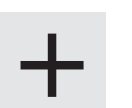

Gynaecology started developing during the nineteenth century. It is a medical practice concerning the health of the female reproductive system. Many women have undergone a pelvic examination (PE) at some point. A physical examination of the female pelvic organs, the PE can be divided into external examination and internal examination. Even though PEs have involved medical benefits for women, patients' experiences of these examinations present a challenging story. Women in general have a positive attitude towards the idea of the PE, while their experience of the examination itself tends to be more negative, in some cases even traumatic (Jeppesen 1995; Larsen and Kragstrup 1995; Wijma, Gulleberg, and Kjessler 1998). These negative experiences may have severe consequences if they result in delay or avoidance of an examination, resulting in potentially harmful health effects (Hilden et al. 2003). A central cause of women's negative experiences during a gynaecology exam seems to be the hierarchical relationship between the examiner and the patient. Various mechanisms associated with the gynaecological examination situation bring a woman patient into a subordinate position in relation to the examiner. Studies show that social factors such as embarrassment about undressing, worries about cleanliness, body odour, loss of control and fear of pain can contribute to this (Hilden et al. 2003; Oscarsson and Benzein 2002).

Historians have paid attention to how gynaecology was historically based on a male power relation, where women were seen as an 
anomaly from men, and argue that this still affects the gynaecological practice and the relationship between the examiner and the patient (Johannisson 1994; Nilsson 2005; Young 1990). The field of feminist technology studies has shed light on how reproductive technology has been working against the interests of women, for example, in the way reproduction technology is defined as well as developed (Haraway 1999; Layne, Vostral, and Boyer 2010; Lublin 1998; Wajcman 1991). This research strand criticizes how male-designed medical technologies shaped and still shape the experiences of women as patients. Feminist design historians stress that men's superior position in society has been fundamental to how artefacts have been designed (Buckley 1986; Kirkham 1996; Sparke 1995). Here, women have had very little or no influence, even regarding the artefacts that are designed for women and women's needs.

However, there are few studies on women's negative experiences of the gynaecological examination from a design perspective, although medical and health studies point towards the gynaecological examination chair (GEC) (see Figure 1) specifically as one of the central causes for negative experiences during an exam (Larsen and Kragstrup 1995; Wijma and Siwe 2002). In some cases, the mere appearance of the GEC can contribute to women's fear. Before even using the chair, they have worries about not being able to use the chair easily and about the exposure of the body the position involves.

The GEC is originally designed for the male examiner's needs without taking into account the woman's perspective (Johannisson 1994; Kapsalis 1997). Traces of this hierarchical mind-set are still to be found when it comes to how contemporary GECs are designed. For example, one of the worlds' leading manufacturers of medical equipment market their GEC with the text "Developed

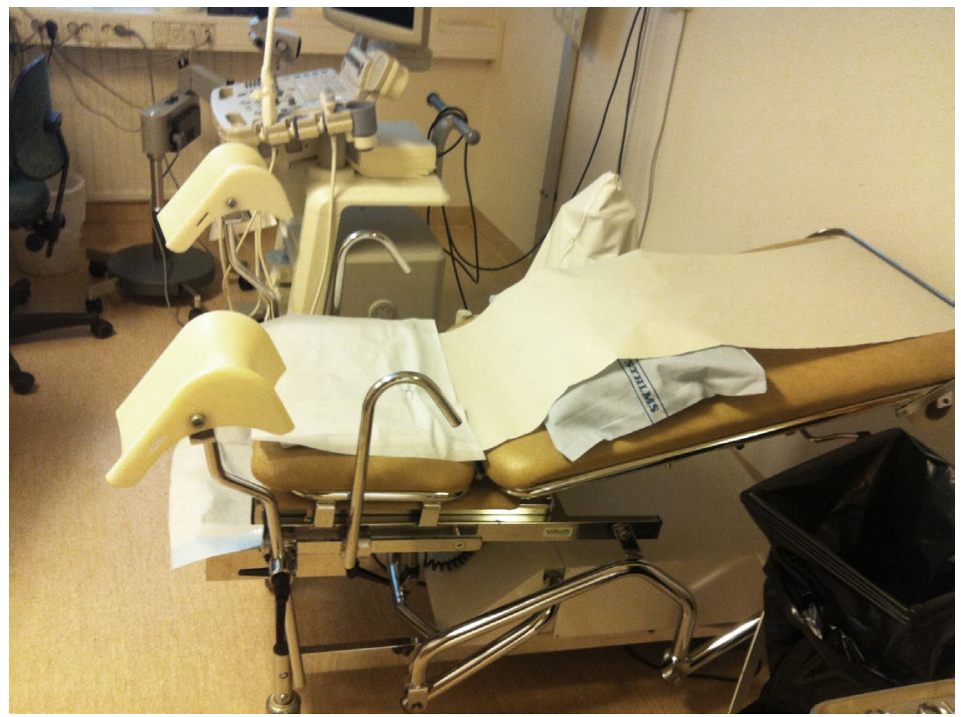

Figure 1

An example of the traditional gynecological examination chair. 
in collaboration with medical staff for best comfort for the patient" (Sjöbloms Sjukvårdsutrustning 2014, our translation from Swedish to English). Yet another manufacturer states "Our gynaecological examination chair is developed together with gynaecologists and industrial designers making the chair functional, easy to use and designed in a stylish design" (Bluebird Medical 2015; our translation from Swedish to English). This could be interpreted as if medical expertise is superior to the perspective of the patient when it comes to design. That is, the medical staff rather than the patient defines what "best comfort" and "functional" means. Thus, the design process of the GEC contributes to the hierarchical relationship between the examiner and the patient. Moreover, this agrees with the traditional design concept of form follows function which feminist design scholars interpret as symbolic of male oppression of women. The machine (the man) takes priority over the body (the woman) (Attfield 1989; Attfield and Kirkham 1989).

In relation to the development towards a more humane approach when it comes the gynaecological examination at large and considering the research on women's experiences of the GEC, the development of the design, in our opinion, has been neglected. Judging from the range of images of the GEC, the design has not changed considerably in the past 100 years. The typical design with stirrups seems to have become customary through the years to the extent that we do not question it.

There are initiatives aimed at strengthening each woman's individual power in order to enable them to take control of the examination (Wijma and Siwe 2002). Although these initiatives are very important, we need to pay attention to the role that the design of the GEC plays in this if we want to take women's experiences seriously.

This paper describes how design can be used as a gender critical practice, firstly to make women's experiences of the GEC more tangible and public, and secondly as a discussion object in order to renegotiate the gynaecological examination and discuss alternative solutions towards a different and more positive experience of the GEC. We have used women's experiences of the GEC as a starting point and essence in the design of an Androchair, a conceptual male equivalent to the GEC. The experiences expressed verbally are transformed into and expressed in and through the design. Putting the experiences in an opposite context compared to how we are used to understanding them changes our relationship to them and offers new perspectives. This urges us to think beyond the genderative thinking of how a "proper" GEC should be designed.

The analysis presented in the article is inspired by the view of the gynaecological examination as a performance where the gynaecological materiality, in our case the Androchair, works as a prop. This introduces the idea that the design of the GEC is an ongoing social process that reaches beyond the materiality, it is a part of a larger context which concerns who has the power and who does not in society. 


\section{Theoretical Starting Points}

The critical design approach has similarities with performance studies. The concept of performance offers a way of comparing social reality with a theatrical play where places are scenes, people are actors and objects are props, all interacting with each other and together creating a story. Depending on the set, different stories can be told (Austin 1975; Derrida 1988; Schechner 2002). This agrees with our idea about the discussion object. Moreover, there is an established discussion within performance studies about how gender is produced (doing gender), which is also relevant considering our gender critical perspective.

In order to demonstrate that sex is not an aspect of what a human being is, but something that is made, maintained and changed in social interaction, Candice West and Don Zimmerman coined the concept doing gender (West and Zimmerman 1987). Several studies have demonstrated how gender is done in other practices than social interactions, extending the focus to (inter alia) texts, technology, symbols, media, art and culture (Buikema and van der Tuin 2009; Faulkner 2001; Gherardi 1995; Kaygan 2014; Nicolosi 2002; Rubin 2001).

Butler proposes the concept gender performativity in the discussion of doing gender. Performativity offers a way of understanding the "highly rigid regulatory frames" (Butler 1990, 33) which steers the acts by the subject. Butler urges us to not only see beyond the subject but to pay attention to our actions that does gender. Going to the gynaecologist regularly is a process of doing gender. Since our actions and thoughts are guided by materiality, we suggest, the GEC becomes a materialized piece that contributes to the regulatory frame for that subject's actions.

Health educator and performer Terri Kapsalis (1997) suggests that the gynaecological examination could be considered as a performance in order to deconstruct our notion of a "proper" gynaecological examination. Kapsalis $(1997,9)$ states:

Gynaecological practices are repetitive and structured to situate the clinician and object of the exam in very specific ways. In this sense, gynaecology is a repeatable performance with specific roles, scripts, sets, costumes and props.

Kapsalis proposes working with the gynaecological examination as a woman-centred performance. Her starting point is women's experiences of the examination and therefore their role as active performers. This way, alternative ideas arise about how gynaecology could be performed in various ways, unique for every woman.

Similarly to Kapsalis, gynaecologists Barbro Wijma and Karin Siwe compare the gynaecological examination situation as a drama where actors, the examiner and the patient, perform a story together (Wijma and Siwe 2002). Wijma and Siwe have developed 
a method aimed at dissolving the hierarchical relationship that the gynaecological examination situation is built upon. By performing the examination in collaboration with the patient, the power is dislocated from the examiner to the patient. For example, just by asking the patient if she wants to be examined, or to ask her if she feels anxious before even entering the examination chair can allow the patient to feel control over the situation and place confidence in the examiner. An important outcome of Wijma and Siwe's study is that it becomes clear that many women seem not to consider that they have the choice or the right to take an active role in the examination situation. They seem to assume that at the same time they seek help with a problem, they have to reject the right to their own bodies. This implicates not only that the gynaecological examination situation is negotiable between the patient and the examiner, but more importantly, that this is performed in a context of power relations.

In this paper, our theoretical outset is inspired by the view of the gynaecological examination practice as a performance, which highlights the idea that it is constructed and open to multiple readings and interpretations. In this process, the design of the GEC plays an important role.

\section{Visualizing the Invisible}

Design can be read as a visual language, a sort of text from which we understand ourselves through (e.g. Krippendorff 2006). In this study, we have been inspired by the notion of performative texts to find critical outlooks for the design process. We use a gender critical design method, originally inspired by philosopher Derrida's term deconstruction which aims to expose and inherent hierarchies in texts. According to Derrida, meaning is defined in terms of binary oppositions, one superior to the other. An example of a binary opposition is the male-female dichotomy where the male is superior to the female. By reversing or displaying these binary oppositions, our relationship to them changes and offers new perspectives (Derrida 1978).

Similar to the purpose of critical design, deconstruction is a way of reading texts with the intention of making these texts question themselves. Previously, this critical design method has successfully been used, e.g. in order to unveil gender-coded design of two common household appliances - a drill and a hand blender (Ehrnberger, Räsänen, and Ilstedt 2012). The product language of the tools was analysed and then exchanged in two new prototypes: the hand blender Mega Hurricane Mixer and the drill Dolphia. By the exchange, the gender and hierarchical values connected to each design and each artefact became critically visible. Since the science of gynaecology by its nature is gendered and, moreover, based on men's power over women's bodies, we found it suitable to use the similar critical design method in order to discuss the correlation between women's experiences of the GEC and the design of the 
GEC. In this paper, we call this the Gender Swapping Method. But instead of using physical and visual material as our starting point for the design process (as in the case of the blender and the drill), we seize the performative dimension of the GEC and therefore start with the patients' experiences of it. Following Wijma and Siwe, as well as Kapsalis, we have strived to dislocate the power of the notion of how a "proper" GEC could be designed.

The study includes three consecutive phases. During the first phase women's experiences of the GEC were explored. In line with the Gender Swapping Method, we also explored the examination situation of men's genitalia, in order to find a comparable situation to women's PE. We carried out informal and semi-structural interviews with 40 women regarding their experiences of a PE. Similarly, we interviewed 10 men about their experiences of an examination of their genitalia. In addition, we interviewed medical staff in order to understand the overall picture of the respective examination situations and to be able to include aspects related to the experiences that the patients could not communicate themselves. From the gynaecological field, the interviews were conducted with two midwives, one registered nurse and one enrolled nurse, two senior physicians, specializing in gynaecology and obstetrics. They were all women. From the andrological field, the interviews were conducted with one senior physician and two nurses and one senior physician specializing in urology. All except one were men. Most of the interviews were audio-recorded, while others were documented as written notes by the interviewer.

During the second phase, an Androchair, a male equivalent of the GEC, was designed based on our findings. Finally, in the third phase, the Androchair was displayed for an audience as a discussion object. These phases will now be described in detail.

\section{Ladies' Examination}

The results of our study on women's experiences of the GEC correspond with previous studies, showing that women in general have positive attitudes to the examination, while the experience itself tends to be more negative. Even though the women we interviewed expressed reluctant feelings towards the gynaecological examination as a whole, the GEC itself was repeatedly expressed as a symbol for the negative experience during the examination. Although we did not explicitly ask about the GEC during the interviews, the interviewed women seemed to have a need to express their reluctant feelings against it. They described the GEC with experiences like "being exposed", "sterile feeling", "obsolete", "cold and harsh". Even stronger associations were used to describe the PE. Descriptions like "rape", "disempowered" and "torture" were used.

The medical staff we interviewed confirmed women's experiences of the GEC - both from the patients' perspective but also from their 
own perspective. Some said that they sometimes felt psychological stress due to the patients' negative experience of the GEC. One nurse expressed her dissatisfaction regarding the difficulties when placing the patient in the correct examination position. The problem, she explained, is that she must repeatedly ask the patient to come further and further down with their bottom. She continued by explaining: "When the patient feels that she is almost tipping out of the chair - that is the perfect position for me!"

One aspect that all medical staff pointed out as an important issue was that some women have experienced sexual abuse and rape, sometimes conducted in the same body position required by the GEC. Entering the chair can therefore bring forth traumatic memories and anxiety for these women. In some cases, an examination cannot be conducted at all and the medical staff have no other alternative than to send the women home.

Even though women and medical staff both expressed reluctance towards parts of the examination routines and the GEC in specific, they did not question it. On the contrary, the women seemed to adapt to it. For example, one woman explained that she always wore a skirt when attending exams to "facilitate the ascendance into the GEC". Another woman brought her own hot-water bottle, which she placed on her stomach before examinations to relieve eventual pain. Yet another woman expressed that her reluctant feelings were "a part of the experience", which indicates not only that she had accepted these negative feelings but seemed to see them as a definition of what it involves to be examined.

\section{Gentlemen's Examination}

Our study showed that the examination of men's genitals inside the body, for example the prostate, was the most comparable to a PE. Before an examination, men are usually asked to stand with their back towards the doctor and to bend over a bunk. In some cases, they lay down on the side on the bunk, with knees pulled up. However, none of those positions were the most optimal for a proper prostate examination according to one of the interviewed physicians. He preferred his patients to lay on their front, headlong, with legs spread and knees pulled up. He called this the "stomach position" (see Figure 2). In that way, he argued, the prostate "dropped down" and became easier to access. This same argument is used for the position the GEC offers, since the uterus becomes easier to access.

The male patients we interviewed described this position as "exposing" and "degrading", just like the women felt about the position of the GEC. One man said the position made him "associate the examination with sexual abuse". 


\section{Making the Androchair}

Following the idea of the Gender Swapping Method we now move on to describe the actual design of the Androchair.

It is of importance to keep in mind that it is not a straightforward matter to compare the ways men and women are examined. Both women's and men's experiences are based on their positions and hierarchy in society. Therefore, we cannot assume that women and men share the same concerns regarding the examination. Our objective by using the Gender Swapping Method is to make women's normative experiences critically visible. Our objective is not to suggest an equal examination chair for men nor an object, which aims to generate same experiences for men as for women. Nonetheless, we do welcome that our critical design object may also visualize and question the different ways in which women and men are examined, based on their particular positions in society.

Consequently, we did not strive for objectivity by looking at the GEC expressly from a design perspective and then transfer the design to an Androchair. As the interviews show, the values and the hierarchical thinking in the design of the GEC seem to have become an invisible and accepted norm. The stories would not be visible in that way. Instead, the empirical findings from the interviews, the expressed experiences from the women and to some extent the examiners, served as watchwords in our design decisions. At the same time, we wanted the final design to resemble a real product as much as possible; we wanted it to look realistic and appeal to the audience's imagination.

We have previously described the experiences of the GEC in general, now we will add more detailed description and at the same

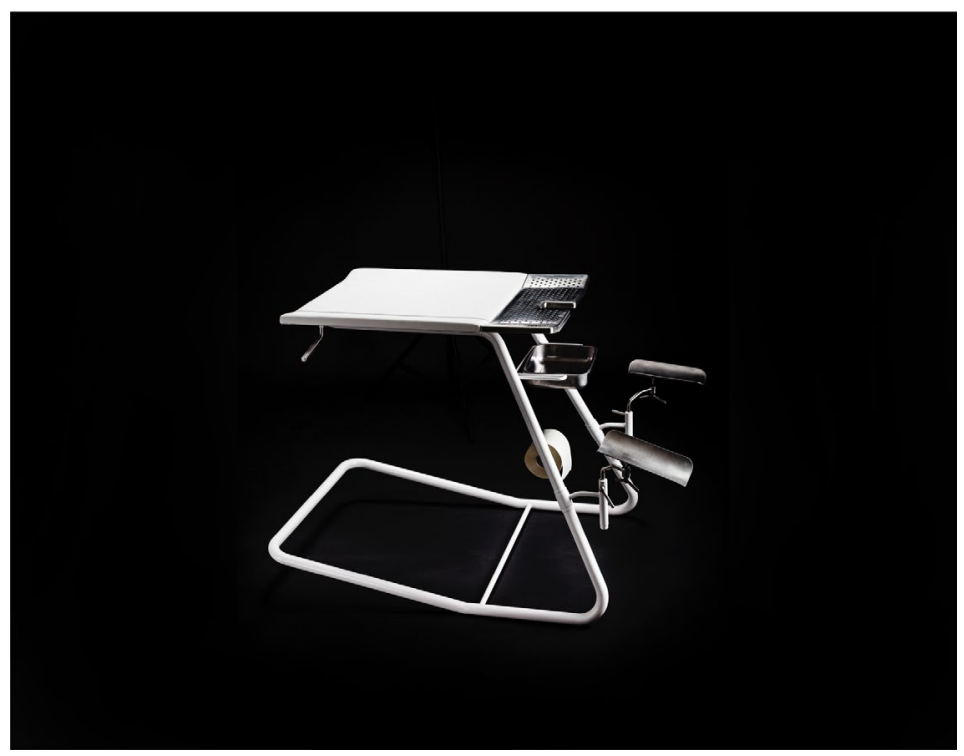

Figure 2

The Androchair. 
time link them to the design of the Androchair, its materials and construction (see Figure 3).

The overall construction of the Androchair is based on the stomach position, which seemed to be the most proper position for prostate examinations, but also the most vulnerable. All proportions are based on the andro-metrics of the average man. This is because nearly every woman we interviewed expressed that they were too big, too small, too short or too tall for the GEC. Some women complained that they were not flexible enough. We believe the same would apply to men's experiences of products designed with an average man in mind.

The materials chosen for the chair were stainless steel and lightly padded synthetic material to bring forth connotations of medical care products.

To be able to ascend the Androchair, trousers must be removed since the legs need to be placed in stirrups, just like for women in the GEC. The stirrups are made of stainless steel with no soft covers. This decision is based on women complaining that the GEC stirrups are harsh and cold. Some women expressed that they became cold when having to expose their stomach in the GEC. Therefore, the bunk is made hard and at the end of it, closest to the lower part of the stomach, it is made from perforated steel for a colder experience.

Once someone is on the Androchair, the whole construction tips forward (see Figure 4). This decision arises directly from the previously mentioned comment from a nurse who stated that the perfect body position for an examiner is when the patient feels almost as if she is tipping out from the GEC. So, when the patient in the Androchair feels that he is about to tip out, his body is in the perfect position from the examiner's perspective.

At both sides of the bunk, beside the patient's head, are two handles with grips. Some GECs have handles on both sides, and some women observed that just seeing them brought forth connotations that something so unpleasant was going to happen that they would have to grip them. They also evoked feelings of being controlled, since they encourage the patient to keep their hands away from the examination area. Moreover, when gripping

\section{Figure 3}

The "stomach position".

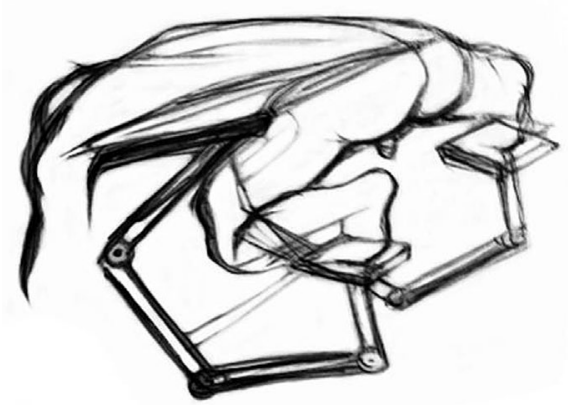




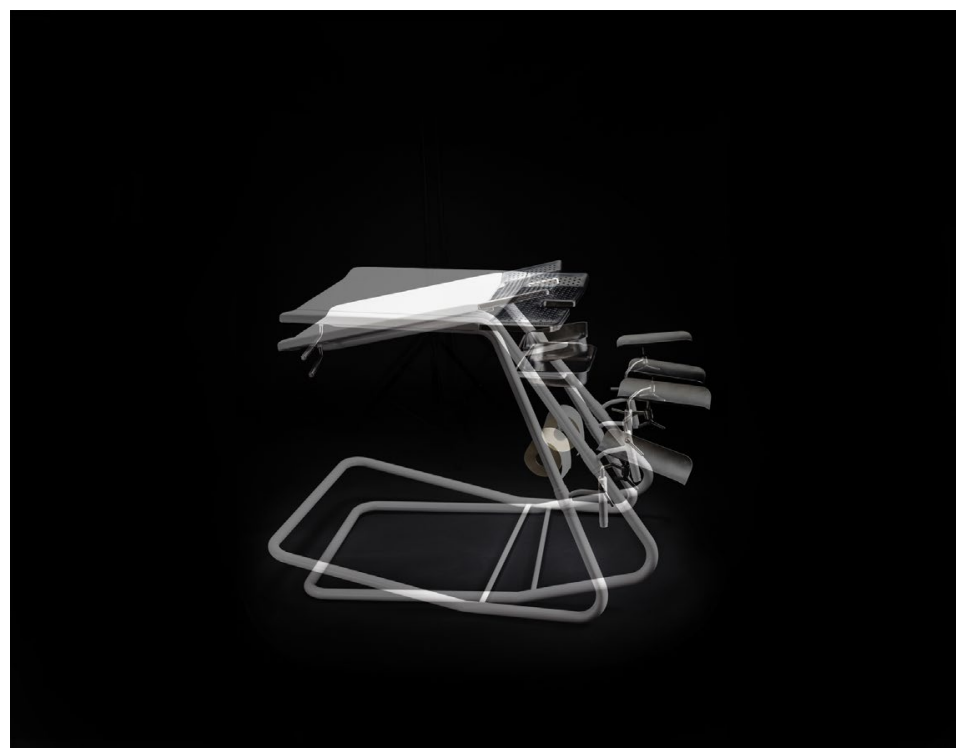

Figure 4

The tipping effect.

them, they were too big and did not feel very pleasant in the hand. Consequently, the handles on the Androchair were designed for small hands.

Underneath the bunk is a tray for examination instruments and bodily waste from the examination, similar to those that can be found on the GECs. Moreover, there is a paper holder to remind the user of hygiene aspects but also the messy and uncomfortable parts of the examination, similar to the big paper rolls on the GECs. This mixture of attributes was specifically pointed out as "unworthy" and "unpleasant" by some of the women.

Finally, some of the interviewed women expressed that the worst experience when lying in the GEC was that they felt "trapped" and "out of control", they did not experience that they had the choice to break the examination and step down whenever it felt wrong or painful. In addition, they expressed that this feeling was reinforced by the fact that they could not see what was going on "down there". To create the same feeling when lying in the Androchair, we made it impossible for the patient to descend from the chair himself. Only when the examiner tips the Androchair back to its original position is the patient able to descend.

\section{Said about the Androchair}

The performative dimension is argued to be context-dependant (Austin 1975; Butler 1997; Derrida 1988). So is the result of our study dependant on the context in which we choose to present the Androchair. In this phase of the study, our aim was to extract the existing discussion of women's experiences of PEs from 
an academic and medical context into a broad public space of analysis and critique. Even though our focus was on design, we wanted to shed light upon the idea that everybody from politicians, physicians, patients and designers are co-actors in the performance of gynaecology (which provokes the experiences).

We arranged a seminar at The Swedish Centre for Architecture and Design in Stockholm on 8 March 2013. The invitation was public but key people were personally invited. The seminar was led by a political journalist. There was a discussion panel with a researcher in design and innovation, a researcher in gender studies with focus on women's sexual health, a researcher in gender and innovation studies, and a senior physician specialized in obstetrics and gynaecology. In the audience were journalists from newspapers and specialist magazines, nurses, practicing designers, design students, representatives from a research funding agency, entrepreneurs, politicians and the public. In addition, some of the interviewees from the earlier phases of the study were also present. A total of 60 people participated in the seminar, both men and women, although predominantly women.

The seminar opened with an introduction to design research and design as a critical tool for discussion. Then the study and the Androchair were presented. The Androchair was physically present on stage during the entire seminar. Next, discussions took place both with the panel and the audience. At the end of the seminar, participants were invited on stage to try the Androchair and to share their reflections.

The Androchair stimulated various topics ranging from gynaecology as a medical practice to political issues regarding health and gender. However, in this paper, we concentrate on giving account of the design perspectives that the participants emphasized.

Three key areas stood out at the seminar. These involve the use of the chair and in particular were considered as contributing to a negative experience of the gynaecological examination as a whole. Here, we present them as possible areas for renegotiating the gynaecological examination. The reader should keep in mind that these three areas are closely intertwined and influence each other. However, for clarity reasons, we will discuss each of them separately.

We will also give an account of some concrete suggestions that the seminar participants contributed on how these challenges could be renegotiated through design. This exemplifies the potential of gender critical design as a co-actor in the renegotiation of the gynaecological performance.

\section{Renegotiating Power}

The participants agreed that the body position the GEC requires is one of the main reasons why the patient feels subordinate to the examiner. This finding also corresponds with previous studies (Wijma and Siwe, 2002). In order to renegotiate the power relations between 
the patient and the physician, the participants suggested a flexible construction of the GEC, which can offer the patient different body positions in collaboration with the examiner. For example, to avoid negative associations the origin position could be straight up when the patient enters the examination room instead of horizontal. In addition, this would facilitate entrance into the chair. Then, gradually, the GEC could be adapted to the situation.

Another aspect, which participants considered contributed to feelings of being subordinated, was that they were not engaged in the examination of their own body. One woman shared her experience where she had been offered a mirror by their examiners. The opportunity to use a mirror had increased her feeling of engagement. It was suggested that a permanent mirror for the patient was to be integrated as a part of the chair as a way of communicating not only the right to be an active part of the examination but also having control over it.

\section{Renegotiating Experience}

Participants at the seminar emphasized the fact that the experience of a gynaecological examination is a result of how the woman perceives the situation through all her senses. Still, the GEC does not seem to be designed with respect for the experience of tactility, smell, balance, hearing, kinaesthetics and temperature. As many women associate the gynaecological examination situation as something vulnerable, sometimes provoked by earlier experiences of rape or incest for example, this was considered as an extremely important problem that has o be improved in order to decrease the negative experiences.

Apart from the position of the body that the GEC requires (which itself evoked feelings of vulnerability and exposure) participants called for other improvements, such as softer bunks and stirrups, a more stable construction, warmer surfaces and gentle materials.

The discussion also ended up considering what is visible and what is not in the examination room - and why. For example, many women believe that a gynaecological visit by default includes a PE. Sometimes the patient only needs to talk and receive information, or just experience the environment where an eventual examination is supposed to be performed. Therefore, it was suggested that the typical elements that identifies the GEC could be applied gradually, depending on the specific situation and needs. For example, the stirrups, the handles, the waste bowl and the paper cover (which all together seem to paint a rather nasty picture of what is going to happen) could be added to the chair if needed, depending on the situation and in collaboration with the patient. Participants also called for a thorough re-evaluation of these parts of the GEC. The same goes for the examination tools, which often are exposed in the examination room. Participants suggested that they could be hidden in a drawer or under a sheet and exposed one by one when needed. 


\section{Renegotiating Bodies}

The notion of gender is also about our notion of bodies. Our notion of bodies affects the way we look upon and value both physical and psychological needs. At the seminar, participants called for a renegotiation towards a more open and wider interpretation of gender and bodies when it comes to the design of the GEC. This involves problematizing what we define as a "woman" and "women's needs". This in turn means questioning how we value physical, psychological and social factors when the chair is designed. This becomes even more important in our modern society where more individuals define themselves as "in between gender" or even as a third gender. One woman expressed that her body was "not made for the gynaecological examination chair". This statement indicates that she placed herself in a subordinate position compared to the GEC. It also reflects a failure in the design, since the chair should be designed for a multitude of bodies, regardless of one's physique.

In order to design for a multitude of bodies, the solution suggested was similar to the ones regarding power and experience described above. Participants called for a more flexible solution primarily relating to a person's length and weight, but also regarding proportions. This could also be beneficial for the examiners for ergonomic reasons. However, the discussion about the gender issue took a broader turn, ending up in involving gendered needs. Today, some andrology and urology clinics have traditional GECs that are used by people with male genitals for minor operations. Considering the purpose the chair was originally designed for, participants questioned if this was really an optimal solution for those kinds of operations. Seeing it from that perspective awoke an interest in developing a real (not simply a concept) Androchair, designed for the purpose of examining and operating on male genitals. However, considering the risk that this could exclude transsexual or intersexual individuals, this discussion ended by asking if the best solution would be to design a multichair that is more suitable for examinations for both male and female bodies and needs?

\section{Conclusion}

In this paper, we have exemplified how design can be used as a gender critical practice within the context of the gynaecological examination. Our main aim was to make women's experiences of the GEC critically visible in order to discuss alternative solutions. The findings during the first phases of our study were incorporated into the design of an Androchair, a male equivalent to the GEC. Inspired by the view of the gynaecology examination situation as a performance and the Androchair as a prop, we invited people to become active participants at a seminar where alternative performances could be imagined. 
The strength of the Androchair is that it is designed to make women's experiences of the GEC critically visible, while the GEC is not, even if it brings them forward. The GEC, as any other object, is limited by the norms that it exhibits. The Androchair aims to visualize the norm in an emphasized, critical way. By so doing, the Androchair as a discussion object made the audience question their preconceptions and became a source for self-reflection, inspiration and creativity. We believe, that the Androchair served as an instigator to moderate the discussion in a way a GEC would not have. It also served as a material manifestation of the experiences that some women might not or may not have courage to express themselves. Furthermore, we believe that using a GEC would only manifest the female perspective, while the Androchair invites us to think beyond a specific gender as an examination object.

It was not our purpose to suggest a new design for a medical artefact. However, the Androchair did indeed generate alternative design solutions that could contribute to a more positive experience of the GEC. The Androchair illustrated what we accept and do not accept, both regarding examinations for men and for women. This shows how design as a gender critical practice can be used to encourage new ways of thinking about the GEC, its use and the context it is in. By doing so, we can meet people's needs for a more positive experience of the GEC.

However, it is important to bear in mind that the word "alternative" indicates that the solutions deviate from a norm. Therefore, they are not just suggested solutions - they are also simultaneously picturing the ideal patient for the GEC. Bit by bit, she appears. The female who is of average height and weight and who neither is physically nor psychologically disabled in any way. Most likely, she is of average age, sexually active and heterosexual. The question is if this woman really exists. Yet, she constitutes the norm. Seeing it this way, the GEC could be interpreted as an instruction on how women's bodies are expected to be constructed and what they are expected to perform. This agrees with Kapsalis $(1997,6)$ who states:

Gynaecology is not simply the studies of female bodies gynaecology makes female bodies.

Even if a gender critical perspective can lead to new ways to design GECs in the future, the analytical take should not stop here. In accordance with the concept of performance, we should continue to question our gender normative reasoning that comes to light through this critical design practice, since they act in so many dimensions and, moreover, in a context of power relations. Gender normative and hierarchical values that are embedded into the very design of the contemporary GEC simultaneously guide and dictate the design practice. Seeing the gynaecological examination as a performance, and the GEC not only as a prop, but also as a discussion object that 
urges us to investigate and thereby makes designers co-authors in the story of how a "proper" gynaecological examination should be performed. This also means that we have the potential to write and rewrite the story over and over again.

\section{Acknowledgements}

We would like to thank the participants at the seminar and particularly those we interviewed for participating in this research. The project is coordinated and carried out by Centre of Health Technology at Halmstad University. We gratefully acknowledge Vinnova Sweden's innovation agency for the financial support but also for encouragement. We thank our colleagues Sara Ilstedt, Ylva Gislén and Loove Broms for valuable insights during the research.

\section{Disclosure Statement}

No potential conflict of interest was reported by the authors.

\section{ORCID}

Karin Ehrnberger (D) http://orcid.org/0000-0003-3386-2144

Emma Börjesson (D) http://orcid.org/0000-0002-5189-9541

\section{References}

Attfield, J. 1989. "Form/Female Follows Function/Male: Feminist Critique of Design." In Design History and the History of Design, edited by J. Walker, 199-225. London: Pluto Press.

Attfield, J., and P. Kirkham. 1989. A View from the Interior: Women and Design. London: Women's Press.

Austin, J. L. 1975. How to Do Things with Words. Cambridge: Harvard University Press.

Bluebird Medical, A. B. 2015. Instrument/Utrustning. November 6. http://www.bluebirdmedical.se/undersokningsbrits-sl-elektrisk47518.html

Buckley, C. 1986. "Made in Patriarchy: Toward a Feminist Analysis of Women and Design." Design Issues 3: 3-14.

Buikema, R., and I. van der Tuin. 2009. Doing Gender in Media, Art and Culture. London: Routledge.

Butler, J. 1990. Gender Trouble: Feminism and the Subversion of Identity. New York: Routhledge.

Butler, J. 1997. Excitable Speech: A Politics of the Performative. New York: Routledge.

Derrida, J. 1978. Writing and Difference. London: Routledge.

Derrida, J. 1988. "Signature Event Context." In Limited Inc. Illinois: Northwestern University Press.

Ehrnberger, K., M. Räsänen, and S. Ilstedt. 2012. "Visualizing Gender Codes in Design: Meet the Mega Hurricane Mixer and Drill Dolphia." International Journal of Design 6 (3): 85-98. 
Faulkner, W. 2001. "The Technology Question in Feminism: A View from Feminist Technology Studies." Women's Studies International Forum 24 (1): 79-95.

Gherardi, S. 1995. Gender, Symbolism and Organizational Cultures. London: Sage Publications.

Haraway, D. 1999. The Virtual Speculum in the New World Order', Revisioning Women, Health and Healing. New York: Routhledge.

Hilden, M., K. Sidenius, J. Langhoff-Roos, B. Wijma, and B. Schei. 2003. "Women's Experiences of the Gynecologic Examination: Factors Associated with Discomfort." Acta Obstetricia Gynecologica Scandinavica 82 (11): 1030-1036.

Jeppesen, U. 1995. "Kvinders holding til den gynaekologiske undersogelse [Women's Attitudes towards Pelvic Examination]." Ugeskrift for Laeger 157 (12): 1651-1654.

Johannisson, K. 1994. Den mörka kontinenten: kvinnan, medicinen och fin-de-siècle [The Dark Continent: The Woman, the Medicine and Fin-de-siècle]. Stockholm: Norsteds.

Kapsalis, T. 1997. Public Privates: Performing Gynecology from Both Ends of the Speculum. Durham: Duke University Press Books.

Kaygan, P. 2014. "'Arty' versus 'Real' Work: Gendered Relations between Industrial Designers and Engineers in Interdisciplinary Work Settings." The Design Journal 17: 73-90.

Kirkham, P. 1996. The Gendered Object. Manchester, NH: Manchester University Press.

Krippendorff, K. 2006. The Semantic Turn- a New Foundation for Design. New York: Taylor \& Francis.

Larsen, S. B., and J. Kragstrup. 1995. "Experiences of the First Pelvic Examination in a Random Sample of Danish Teenagers." Acta Obstetricia et Gynecologica Scandinavica 74 (2): 137-141.

Layne, L., S. Vostral, and K. Boyer. 2010. Feminist Technology Women, Gender and Technology). Illinois: University of Illinois Press.

Lublin, N. 1998. Pandora's Box: Feminism Confronts Reproductive Technology. Washington: Rowman \& Littlefield.

Nicolosi, A. M. 2002. "Doing Technology, Doing Gender: Teaching Gendered Technoculture." Gender Issues 20 (4): 55-64.

Nilsson, U. 2005. Det heta könet- Gynekologin i Sverige kring förra sekelskiftet [Gynaecology in Sweden at the Last Turn of the Century]. Stockholm: Wahlström \& Wistrand.

Oscarsson, M., and E. Benzein. 2002. "Women's Experiences of Pelvic Examination: An Interview Study." Journal of Psychosomatic Obstetrics \& Gynecology 23 (1): 17-25.

Rubin, D. 2001. "Enacting Gender Identity in Written Discourse: Responding to Gender Role Bidding in Personal Ads." Journal of Language and Social Psychology 20 (4): 393-418.

Schechner, R. 2002. Performance Studies: An Introduction. London: Routledge. 
Sjöbloms Sjukvårdsutrustning, A. B. 2014. Gynstolar. Accessed April 25 2015. http://www.sjobloms.com/produkter/gynekologi/ gynstol.htm

Sparke, P. 1995. As Long as It's Pink: The Sexual Politics of Taste. London: Pandora Press.

Wajcman, J. 1991. Feminism Confronts Technology. Cambridge: Polity Press.

West, C., and D. Zimmerman. 1987. "Doing Gender." Gender and Society 1 (2): 125-151. Sage Publications, London.

Wijma, B., and K. Siwe. 2002. "Empowerment I Gynstolen. Teori, Empiri Och Möjligheter [Empowerment in Gynaecological Examination Chair. Theory, Empiricim and Possibilities]." Kvinnovetenskaplig Tidskrift 23 (2-3): 61-75.

Wijma, B., M. Gulleberg, and B. Kjessler. 1998. "Attitudes towards Pelvic Examinations in a Random Sample of Swedish Women." Acta Obstetricia Gynecologica Scandinavica 77 (2): 422-428.

Young, I. 1990. Throwing like a Girl and Other Essays in Feminist Philosophy and Social Theory. Bloomington: Indiana University Press.

\section{Biographies}

Karin Ehrnberger is currently doing her PhD in Product Design at Royal Institute of Technology (KTH). Her research explores different ways of integrating a norm critical perspective in the design process by questioning the sociocultural context in which design is defined.

Minna Räsänen has a PhD in Media Technology. Currently she is head of School of Communication, Media and IT at Södertörn University. Her research begins with an anthropological interest in understanding human beings in organisations and in society.

Emma Börjesson is a project coordinator at Health Technology Centre at Halmstad University. She has extensive experience to identify, initiate and manage product development projects in health technology.

Anne-Cristine Hertz is currently Manager for a project team at Health Technology Centre at Halmstad University that has the resources to support the development of products and services within the Health Technology area.

Cristine Sundbom has a MA in Industrial Design and has previously studied gender and political science. In her research she is exploring aesthetic driven design as a norm critical practice.

\section{Address for Correspondence}

Karin Ehrnberger, Royal Institute of Technology, School of Machine Design, Brinellvägen 83, 10044 Stockholm, Sweden.

Email:karineh@kth.se 